\title{
Exploration of Nonlinear Dynamics in Boost MPPT for a Solar PV System
}

\author{
Subashini. M, Ramaswamy. M \\ Department of Electrical Engineering, Annamalai University, Annamalai Nagar-608 002, TamilNadu, India.
}

\begin{abstract}
The paper attempts to analyse the nonlinear dynamics of a dc$\mathrm{dc}$ boost converter applied as a maximum power point (MPP) tracker for a solar panel. The MPPT becomes crucial for any solar PV system to exploit the maximum available power in addition enjoying the long-time investment benefits of a solar PV system. The dc-dc converters used for tracking MPP encounter sub-harmonic oscillations owing to variations in the irradiation and temperature and therefrom lead to bifurcation and chaos. The system experiences a deteriorating performance and necessitates exploring the phenomena in the perspective of a MPPT control framework. The focus envisages a study of the stable periodic operation and/or chaotic operation of the converter under different values of irradiation through continuous and discrete time domain waveforms and phase portraits of the state variables. The investigations include evaluating the performance through simulation for different values of irradiation and provide a predictive foray for illustrating the suitability of the use of the system in practice.
\end{abstract}

Keywords: Solar PV, MPPT, Boost converter, chaos, bifurcation, nonlinear dynamics

\section{INTRODUCTION}

The energy-environment challenge of the developing countries continues to be crucial for balancing the economic growth and sustainability [1]. The energy consumption of both the residential and the industrial utilities appears to experience an enviable growth and furores to decide the economic growth in the electricity market [2]. The ecosystems on the other hand affect the natural balance in the oxygen and water cycles of the planet and lead to the threats for the existence of the mankind [3].

The futuristic vision owes to be shaped by the awareness of the global threats along with the guidelines for ecological maintenance, a framework of policies, practices and incentives towards the framework [4]. The use of renewable energy conversion systems overcome global warming, greenhouse gas emissions and increase its share in the energy mix of the developing nations thereby contributing to their economic growth [5].

The distributed energy systems emerge to be a promising alternative for the sustainability development for reducing the huge transmission losses associated with electricity supply to industrial facilities and some residential communities [6]-[7]. The solar photo voltaic (PV) reflects to influence the trend [8] and the theory of maximum power point tracking (MPPT) control corners to be the key technology of solar power generation to ensure the exploitation of the maximum power from the PV module at all operating points [9].

A dc-dc converter serves as an interface between the array and the load and the variation of the duty cycle enables the PV module to operate at the peak power voltage and allow the maximum current to be drawn from it [10]. It represents a kind of nonlinear dynamic system and exhibit an unforeseen long term state of disorder known as chaotic behaviour [11].

\section{RELATED WORK}

The analysis of buck converter under the current and the voltage mode control has been studied in [12] and [13]. The bifurcation behaviour of buck and boost converters operating in discontinuous conduction mode has been investigated in [14] and [15] respectively. The analysis on the chaotic behaviour of a current controlled buck-boost converter with soft switching and hard switching has been explained in [16]. The dependence on chaotic instabilities of the buck-boost converter on the load characteristics has been detailed in [17]. The Cuk converter have been analysed in [18] and have been reported to portrait the status from periodic to chaotic behaviour through period doubling. A current mode controlled negative output elementary Luo converter operating in its continuous conduction mode has been analysed in [19] with reference current as bifurcation parameter. The system has been observed to show a periodic behaviour for low values of reference current and as the values has increased the system has moved into chaotic region via period doubling.

The dynamic characteristics for each topology of the converters along with its choice of the parameters, operating mode, and the control methodologies have been seen to be unique. The dynamics has been analysed using nonlinear modelling techniques and a comprehensive review of the procedures studied in [20]. The dc-dc converters applied as MPP trackers in a solar PV system have a different perspective of control and together with it being a nonlinear source the analysis of the nonlinear dynamics of the complete energy conversion system has been interesting to offer a path for the design and control of the PV system.

Despite the developments the challenges surface to be surmounting and invite still better control formulation for ensuring a stable operation and compliance of an effective delivery of power to the load in the solar PV driven system. 


\section{PROBLEM FORMULATION}

The focus orients to explore the emergence of chaotic phenomenon in a solar PV system due to changes in the irradiation and its consequent unstable operation of the system interfaced with a boost converter. It engages the artefacts of a state space model to form the platform for intriguing the nonlinear operation of the system. The exercise extends to examine the performance through simulation and project the periphery to limit the operation of the system.

\section{SYSTEM MODELLING}

The system in Fig. 1 uses a $250 \mathrm{~W}$ solar panel made from a SRP-250-6PB of seraphim material, with the open circuit voltage and the short circuit current for the panel to be $37.1 \mathrm{~V}$ and 8.92 A respectively. The MPP voltage and current of the panel measure to be $29.9 \mathrm{~V}$ and $8.35 \mathrm{~A}$ respectively. The solar panel modelling follows from a single diode equivalent circuit [21], includes the boost converter parameters to be $C_{i n}=22 \mu \mathrm{F}$, $\mathrm{L}_{1}=0.5 \mathrm{mH}, \mathrm{C}_{\mathrm{o}}=47 \mu \mathrm{F}, \mathrm{R}=33 \Omega$ and $\mathrm{F}_{\mathrm{s}}=20 \mathrm{kHz}$ and engages the Perturb and Observe algorithm for controlling the converter [22].

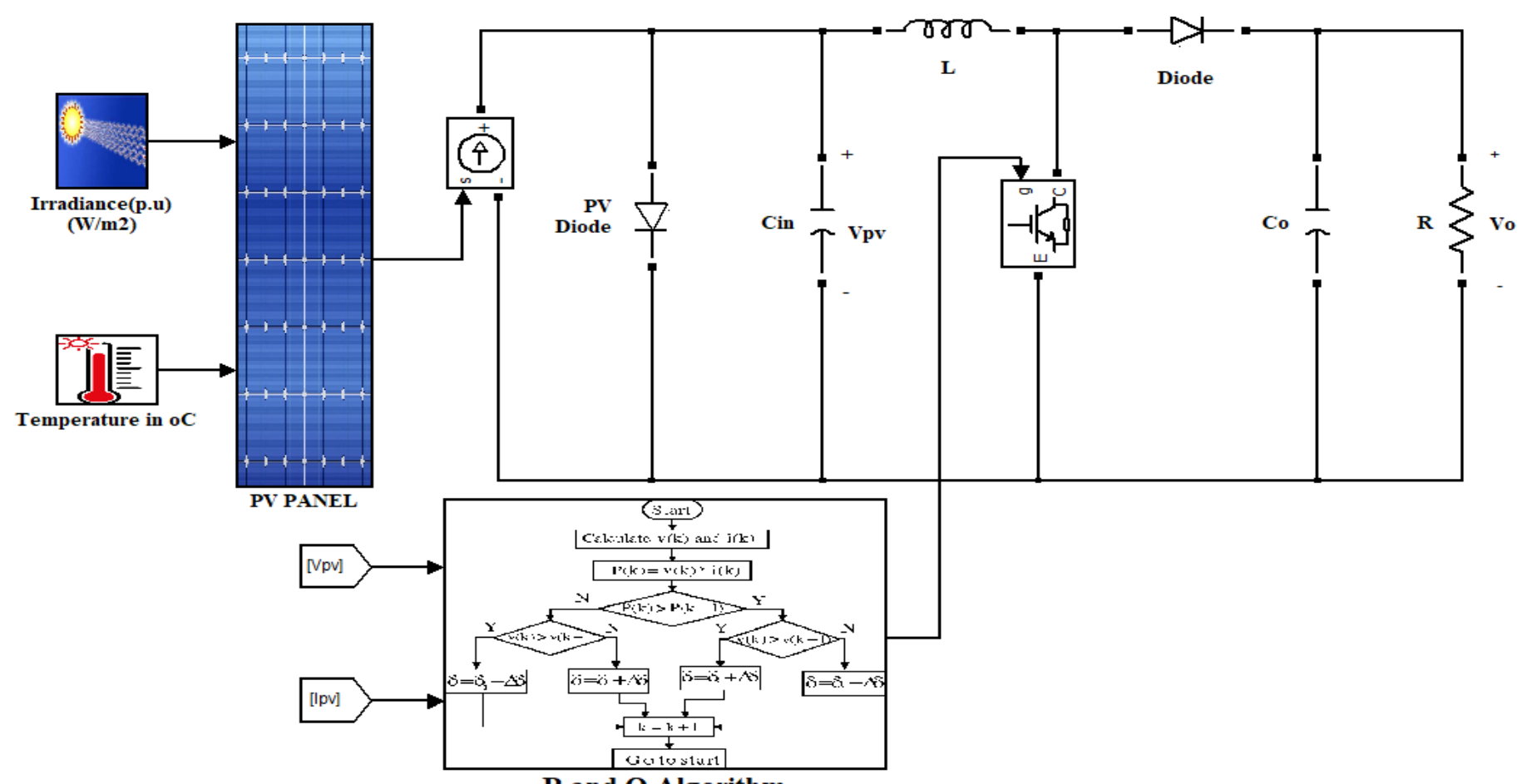

Figure 1. Solar PV fed Boost converter

The state space modelling equations of the boost converter relate as in Eqns (1) to (4)

$\dot{X}=\left\{\begin{array}{cr}A_{o n} X+B_{o n} U ; & n T_{s} \leq t<(n+\delta) T_{s} \\ A_{o f f} X+B_{o f f} U ; & (n+\delta) T_{s} \leq t<(n+1) T_{s}\end{array}\right.$

Where $\delta$ is the duty cycle of the switch and $T_{S}$ is the switching time period

$X=\left[\begin{array}{lll}V_{p v} & i_{L} & V_{o}\end{array}\right]^{T}, U=I_{p v}$ and $P_{p v}=V_{p v} \times I_{p v}$

$A_{\text {on }}=\left[\begin{array}{ccc}0 & -1 / C_{\text {in }} & 0 \\ 1 / L & 0 & 0 \\ 0 & 0 & -1 / R C_{o}\end{array}\right] ; \quad B_{\text {on }}=\left[\begin{array}{c}1 / C_{\text {in }} \\ 0 \\ 0\end{array}\right]$
$A_{o f f}=\left[\begin{array}{ccc}0 & -1 / C_{\text {in }} & 0 \\ 1 / L & 0 & -1 / L \\ 0 & 1 / C_{o} & -1 / R C_{o}\end{array}\right] ; \quad B_{o f f}=\left[\begin{array}{c}1 / C_{i n} \\ 0 \\ 0\end{array}\right]$

The converter switch driven by the duty cycle computed by the $\mathrm{P}$ and $\mathrm{O}$ reflects from Eqn. (5)

$\delta= \begin{cases}\delta_{\text {old }}+\Delta \delta ; & \left(\Delta P_{p v}>0 \text { and } \Delta V_{p v}>0\right) \text { or }\left(\Delta P_{p v}<0 \text { and } \Delta V_{p v}<0\right) \\ \delta_{\text {old }}-\Delta \delta ; & \left(\Delta P_{p v}>0 \text { and } \Delta V_{p v}<0\right) \text { or }\left(\Delta P_{p v}<0 \text { and } \Delta V_{p v}>0\right)\end{cases}$ 


\section{SIMULATION STUDIES}

The study simulates the solar PV fed boost converter modelled from Eqns. (1)-(4) and controlled through the switching law guided by the $\mathrm{P}$ and O MPPT described in Eqn. (5). The procedure involves a repeated stacking of the solution from the previous iteration by a nonlinear mapping of state variables sampled at the chosen switching frequency.

It drives the system at a switching frequency of $20 \mathrm{kHz}$ along with an intermittent control signal frequency generated by the perturbation operation of the $\mathrm{P}$ and $\mathrm{O}$ MPPT algorithm. The duty cycle control signal generated by the algorithm in Fig. 2 oscillates at around $1250 \mathrm{~Hz}$ at $1000 \mathrm{~W} / \mathrm{m}^{2}$ of irradiation and keeps the system at periodic steady state. The rise and fall of inductor current synchronizes with the switching frequency and thus assumes a triangular shape at $20 \mathrm{kHz}$. The triangular inductor current retaining its shape also travel along with control signal to generate a waveform as shown in Fig. 2 which constitutes to be a mix of $20 \mathrm{kHz}$ and a low frequency oscillation of $1250 \mathrm{~Hz}$ and still in periodic steady state.
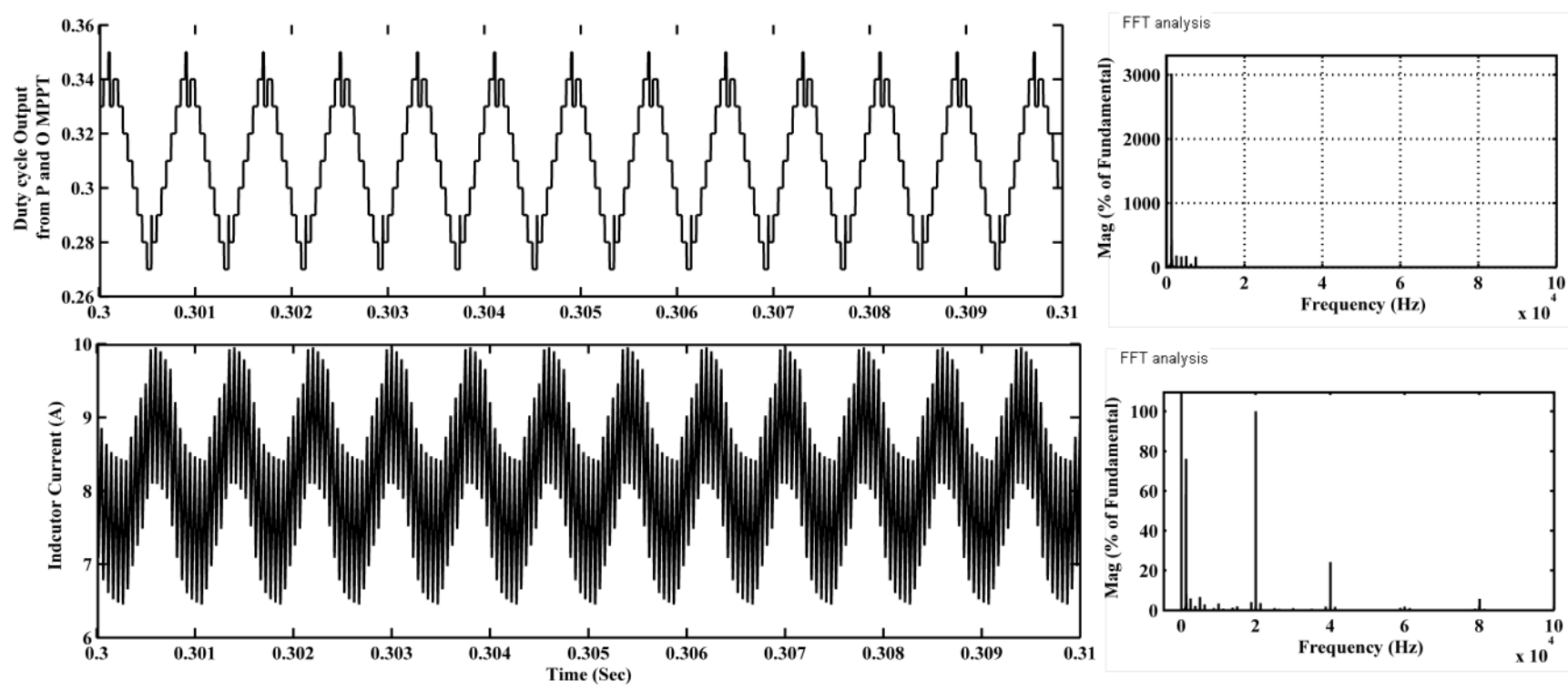

Figure 2. Duty cycle output from $P$ and O MPPT and Inductor current at $1000 \mathrm{~W} / \mathrm{m}^{2}$.

The Figs. 3 to 5 respectively show the continuous and discrete time domain voltage waveforms of the PV panel, the inductor current and the output voltage of the converter at $1000 \mathrm{~W} / \mathrm{m}^{2}$ and depicts the phase portrait of the system at $1000 \mathrm{~W} / \mathrm{m}^{2}$ in Fig. 6. The periodic behaviour of the system at $1000 \mathrm{~W} / \mathrm{m}^{2}$ can be verified through the state variables and phase portraits.
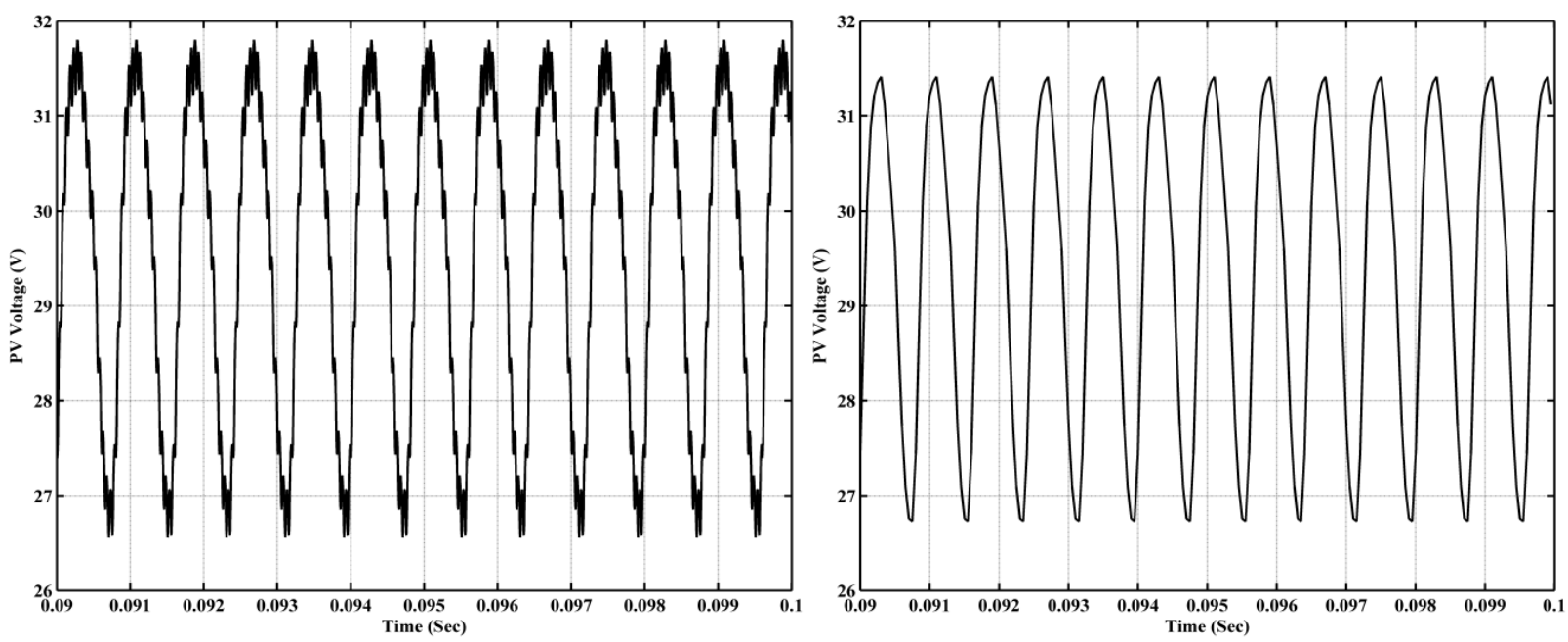

Figure 3. PV voltage input to boost converter at $1000 \mathrm{~W} / \mathrm{m}^{2}$ 

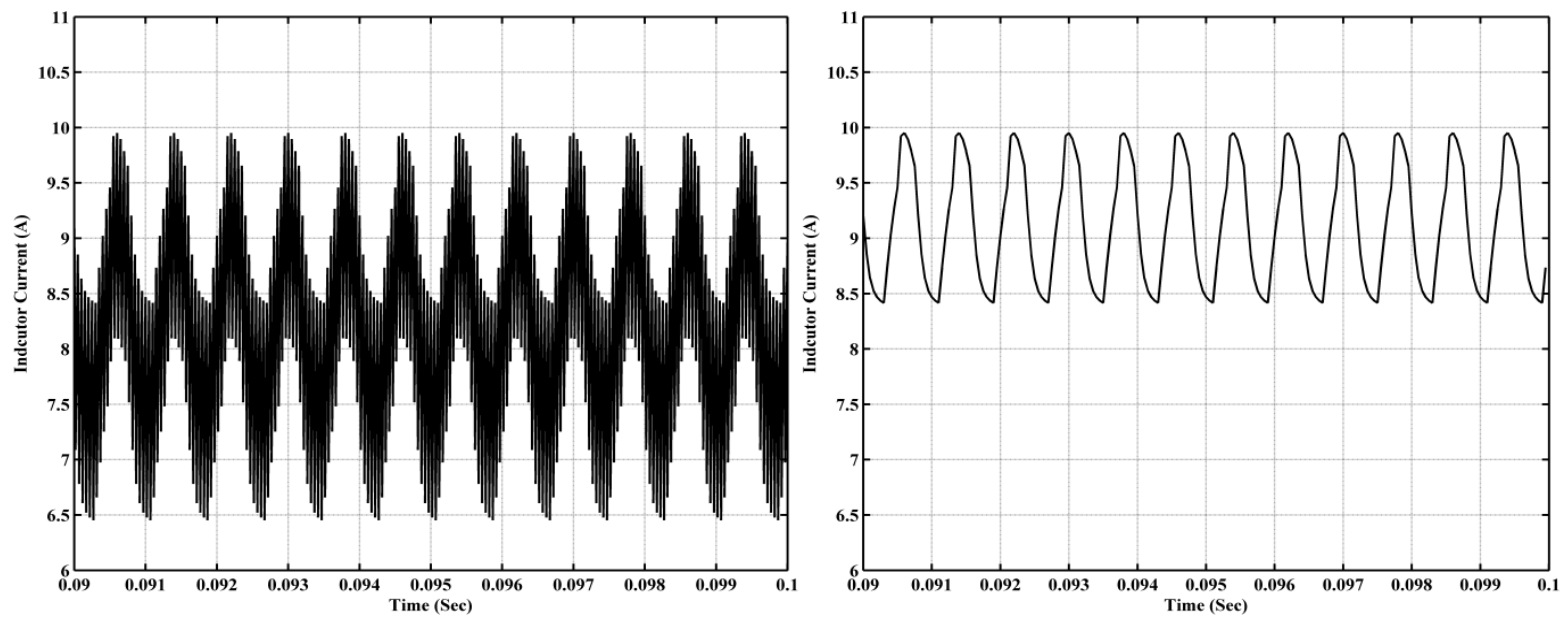

Figure 4. Inductor Current of boost converter at $1000 \mathrm{~W} / \mathrm{m}^{2}$
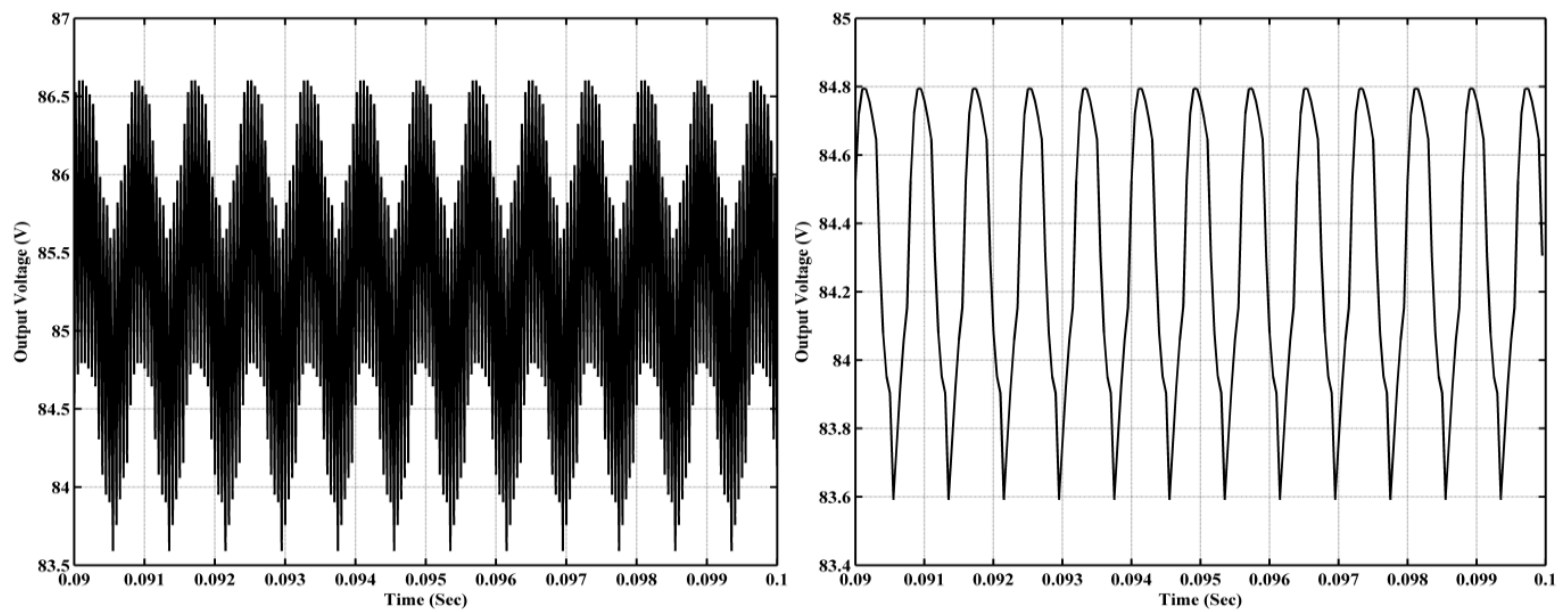

Figure 5. Output voltage of boost converter at $1000 \mathrm{~W} / \mathrm{m}^{2}$

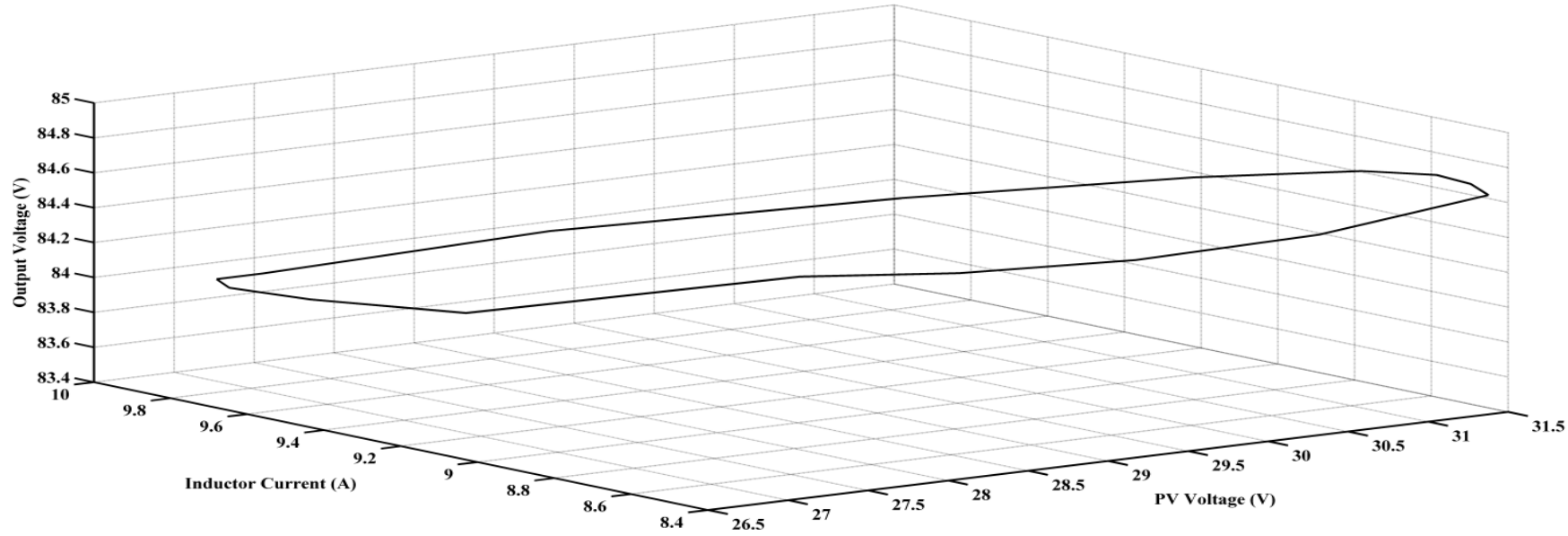

Figure 6. Phase portrait of state variables of boost converter at $1000 \mathrm{~W} / \mathrm{m}^{2}$ 
The irradiation on the solar panel is on peak around 2 to 3 hours of a day in a tropical region and the irradiation around dawn and dusk typically lies around $200 \mathrm{~W} / \mathrm{m}^{2}$ to $600 \mathrm{~W} / \mathrm{m}^{2}$ that spreads over a time period of 8 to 9 hours. It requires the converter to perform MPP tracking all over the period from dawn to dusk and the analyses of the dynamics of system at lower irradiation conditions become significant.
The duty cycle control signal from $\mathrm{P}$ and $\mathrm{O}$ MPPPT algorithm loses its periodicity around $1250 \mathrm{~Hz}$ and becomes chaotic at $200 \mathrm{~W} / \mathrm{m}^{2}$ displaying a wide spectrum of low amplitudes around $1250 \mathrm{~Hz}$ as reflected from the inductor current seen in Fig. 7. It forces the PV system to enter into sub harmonic oscillations driven at the switching frequency entrenched along with chaotic duty cycle control signal.
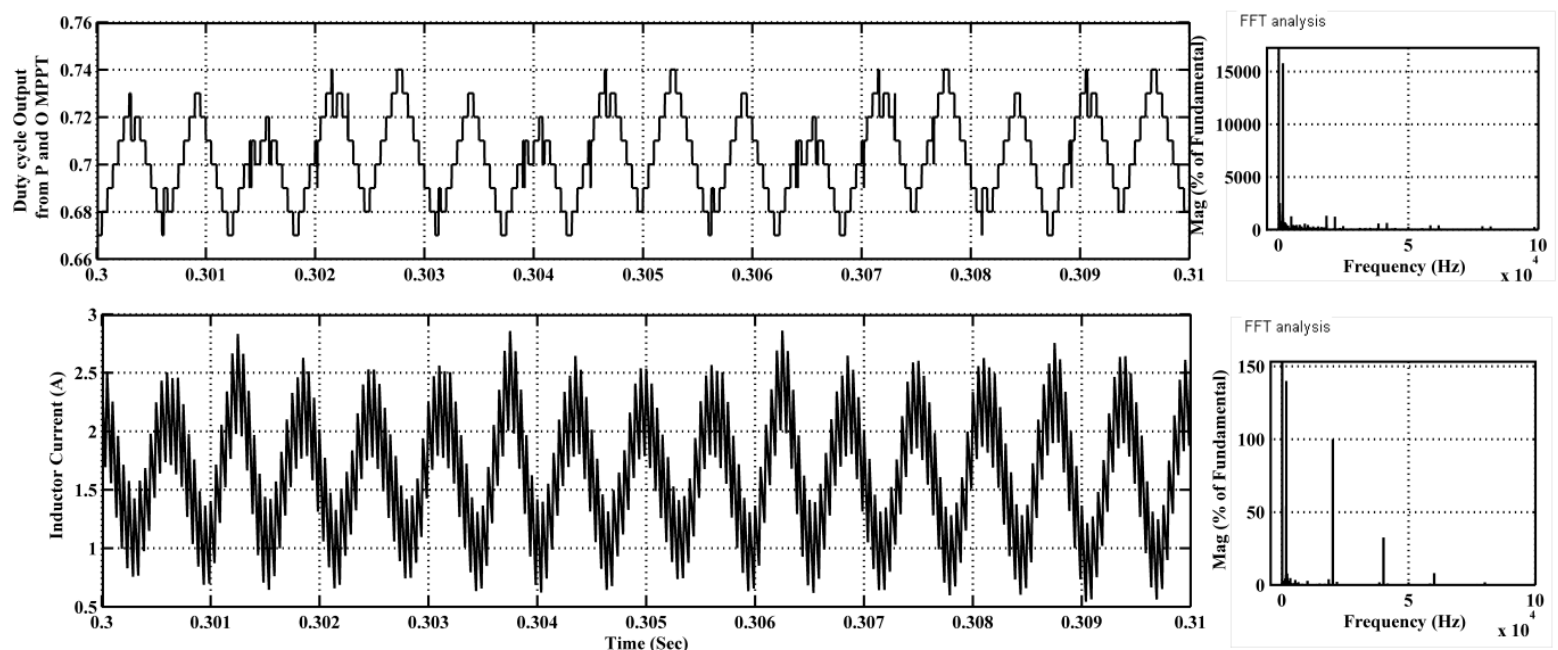

Figure 7. Duty cycle output from P and O MPPT and Inductor current at $200 \mathrm{~W} / \mathrm{m}^{2}$.

The phase portraits visualize the aperiodic behaviour of the PV system through the changes in the state variables. The continuous and discrete time domain waveforms from Fig. 8 to Fig.10 respectively reveals the chaotic behaviour of the PV voltage, inductor current and output voltage of the PV system at $200 \mathrm{~W} / \mathrm{m}^{2}$. The phase portrait of the converter state variables at $200 \mathrm{~W} / \mathrm{m}^{2}$ in Fig. 11 exposes the quasi periodic nature of the PV system.
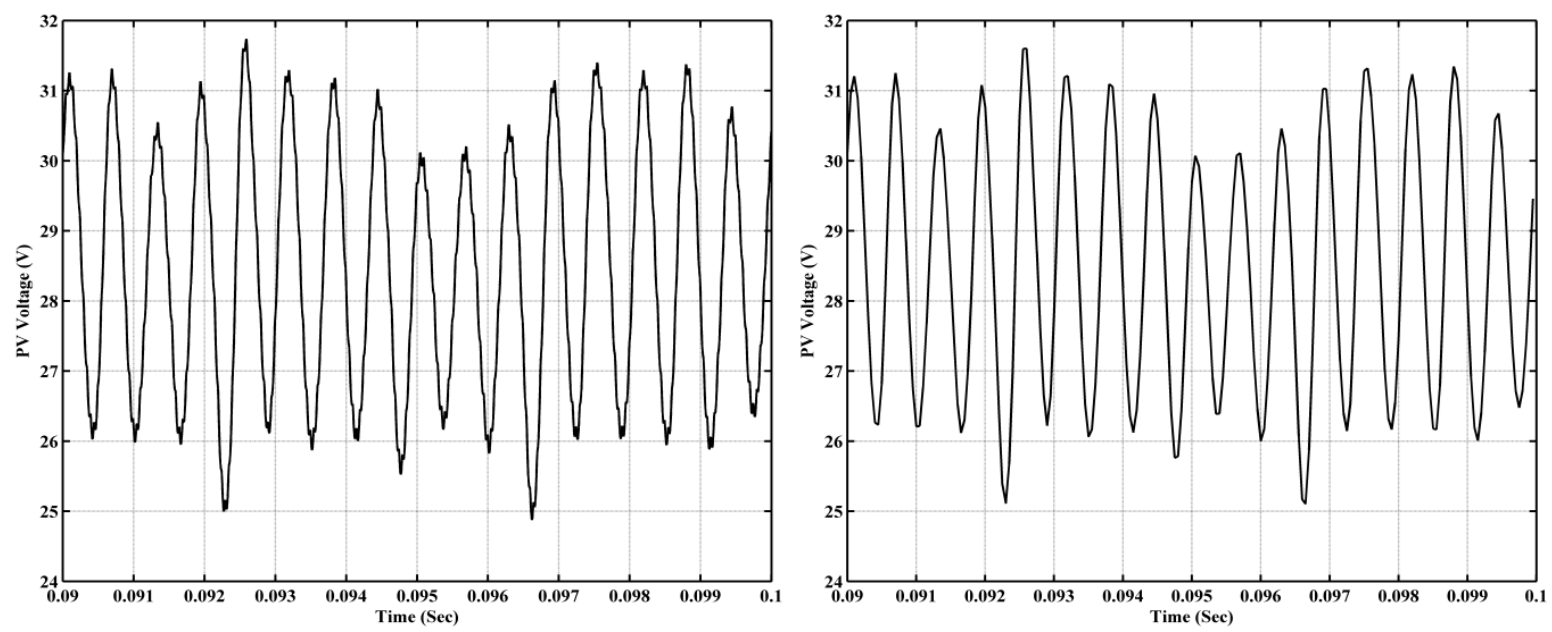

Figure 8. $\mathrm{PV}$ voltage input to boost converter at $200 \mathrm{~W} / \mathrm{m}^{2}$ 

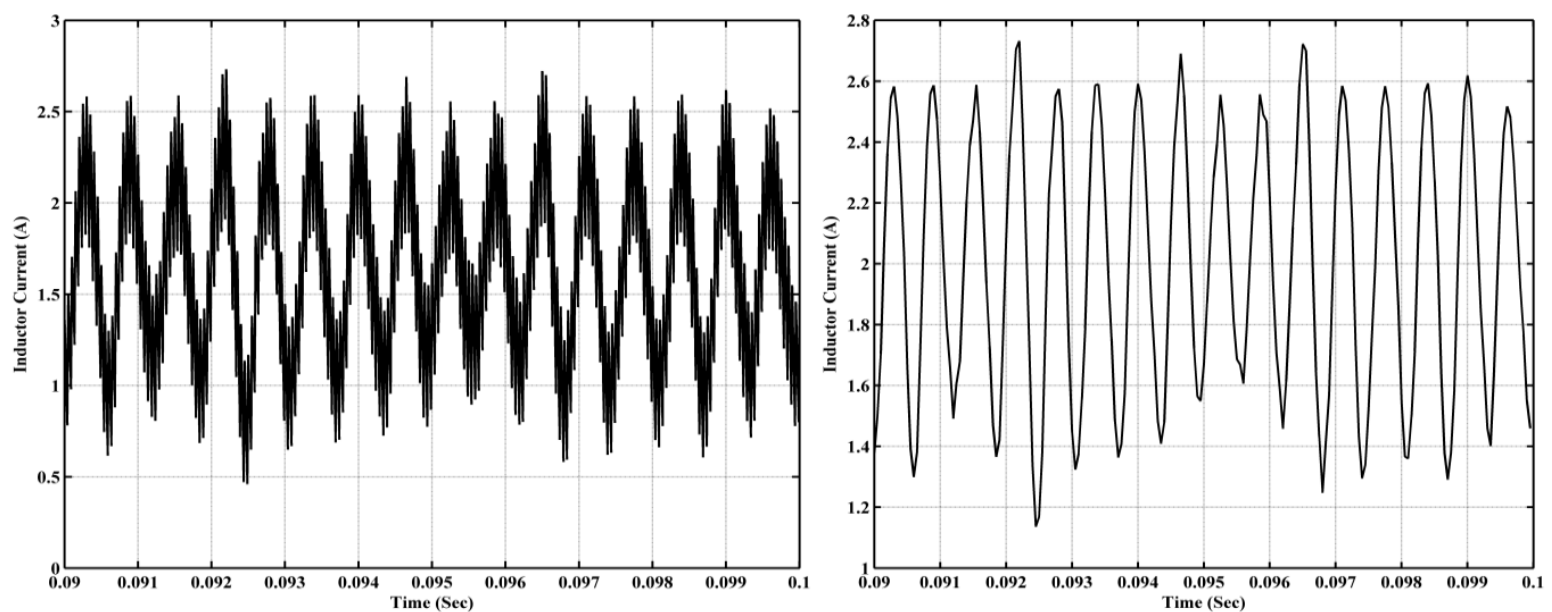

Figure 9. Inductor Current of boost converter at $200 \mathrm{~W} / \mathrm{m}^{2}$
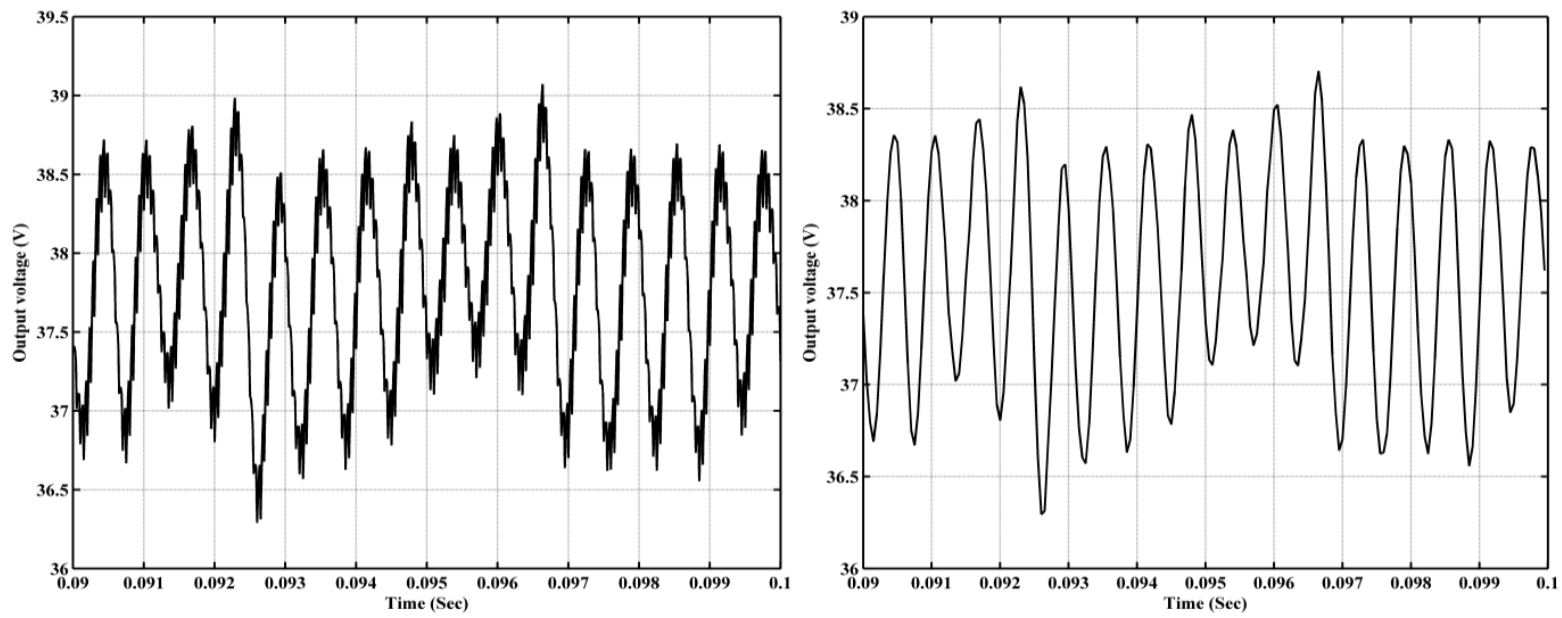

Figure 10. Output voltage of boost converter at $200 \mathrm{~W} / \mathrm{m}^{2}$

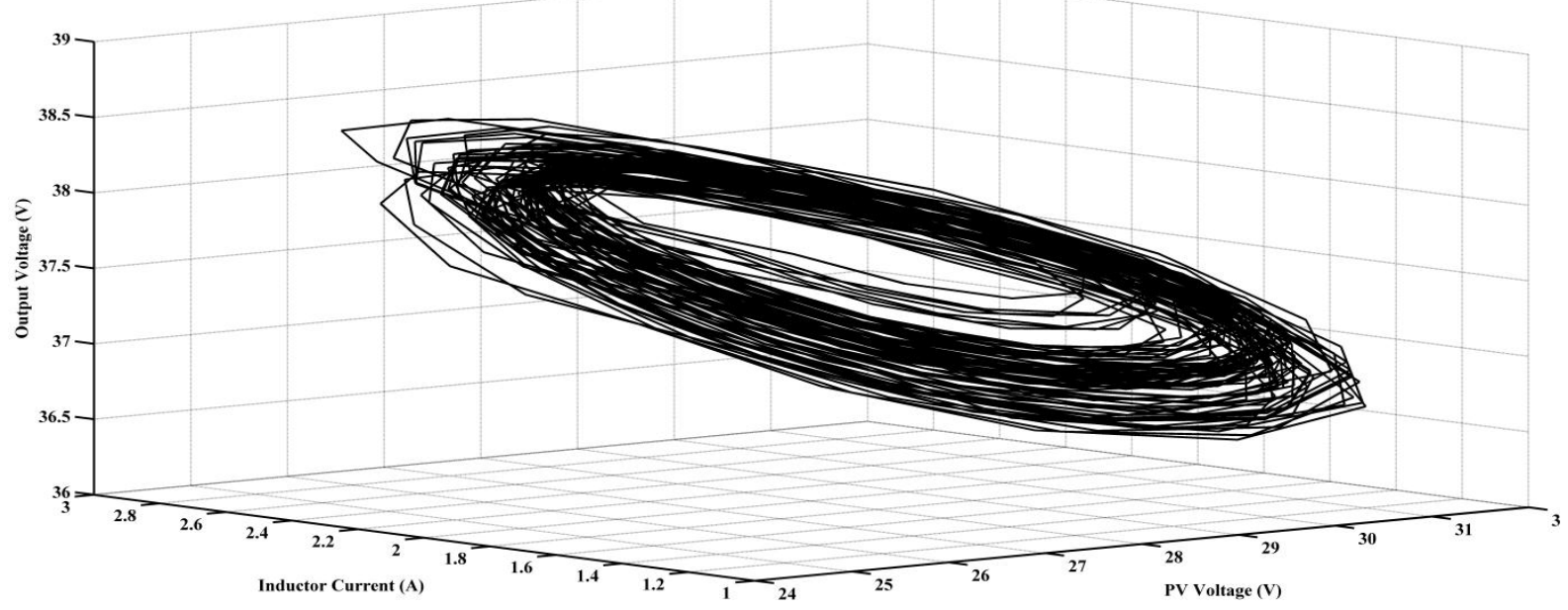

Figure 11. Phase portrait of state variables of boost converter at $200 \mathrm{~W} / \mathrm{m}^{2}$ 
The bifurcation analyses of the complex dynamical systems can be used to study the topological variation in the state variables, boundaries of stable attractors, and distribution of stable and unstable solutions in the state space domain as a control parameter is varied. The exercise envisages studying the bifurcation behaviour of the proposed system by varying the irradiation to locate the stable boundaries.

The bifurcation diagram in general shows the mapping of state variable, sampled at the rate of driving force of the system to a bifurcation parameter. The Fig. 12 shows the bifurcation diagram of the inductor current of the boost converter with irradiation input as bifurcation parameter. On account of the fact that two driving forces that include the switching frequency and the duty cycle control signal from MPPT algorithm drive the system, the bifurcation diagram shows a set of samples per bifurcation parameter instead of a single sample.

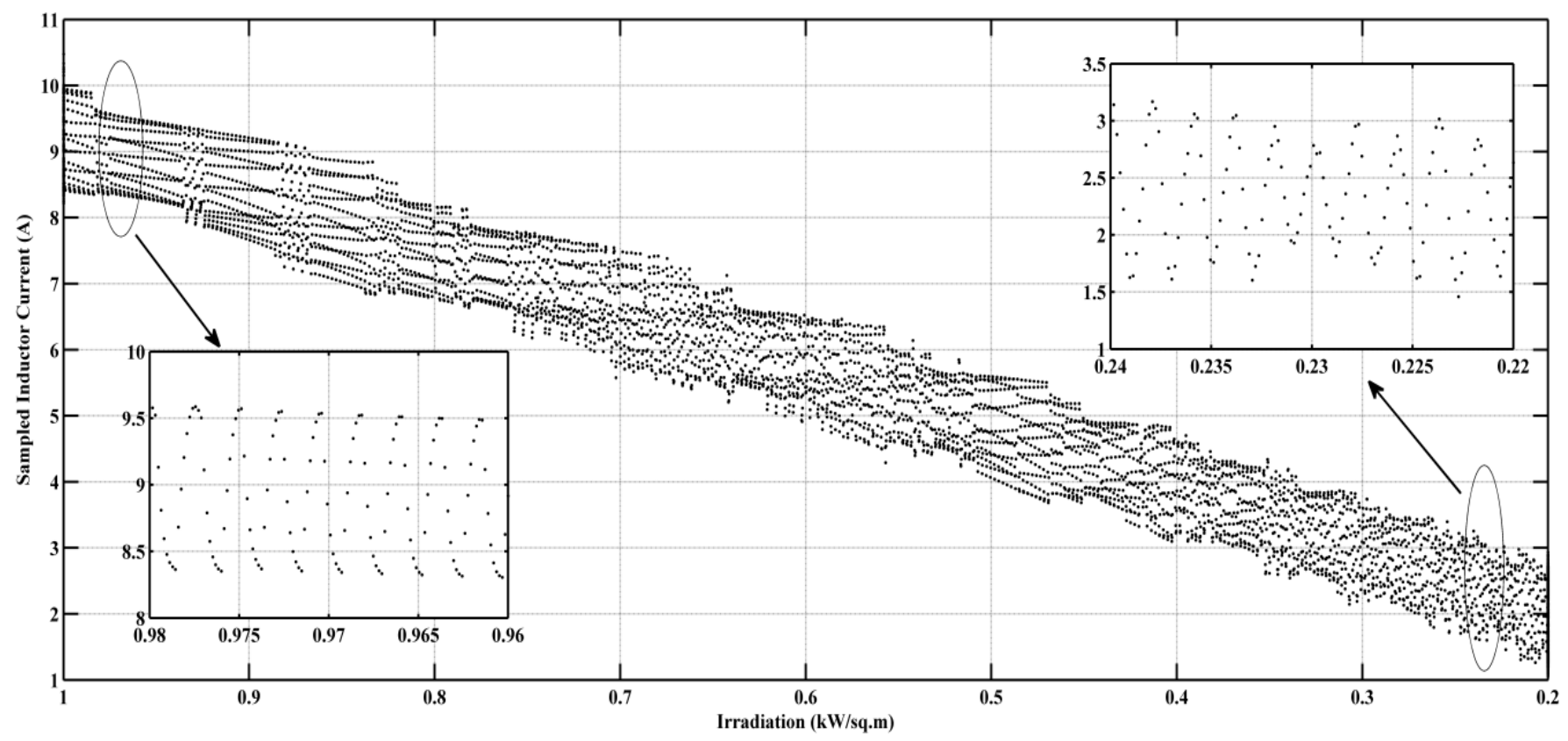

Figure 12. Bifurcation diagram of inductor current of boost converter

However exhaustive analyses of the diagram for small ranges of bifurcation parameter as seen in the sub-plots of Fig.12 reveal details relating to the stability. It can be seen that the PV system sustain in the stable periodic operation from $1000 \mathrm{~W} / \mathrm{m}^{2}$ to $750 \mathrm{~W} / \mathrm{m}^{2}$ and further reduction in irradiation causes an intermittent quasi periodic behaviour which eventually leads to chaos after $350 \mathrm{~W} / \mathrm{m}^{2}$.

The analyses measure the performance of the converter in perspective of a MPP tracker in terms of efficiency of tracking and effective conversion. The nature of $\mathrm{P}$ and $\mathrm{O}$ algorithm serves to find the MPP and oscillate around the MPP. The proper choice of perturbation value and perturbation rate attributes to an efficient tracking algorithm with reduced oscillation around MPP and thus ensuring high average power tracked from the PV panel.

However, the nature of dynamical behaviour of the converter under P and O MPPT control also influences the oscillations around MPP. The output of the boost converter offers power either to a dc load or reaches the dc bus input of an inverter or to charge a battery. In any case the ripple in output of boost converter impinges an adverse effect on the performance of the load or harmonic injection of the inverter and deteriorates the lifetime of the battery. The dynamical characteristics of MPPT boost converter impact the ripple content in output voltage or current of the boost converter.

The Table. I includes the parameters that measure the performance of the MPP tracking boost converter for various irradiation condition. The system tracks the MPP with reduced oscillations for higher values of irradiation and the tracking efficiency turns out to be higher for larger values of irradiation. The scattered order observed in the ripple content of output voltage for various values of irradiation reflects the unpredictable nature of chaotic operation of the PV system. While the conversion efficiency seems to be higher for low values of irradiation, the utilization efficiency, defined as the ratio of the power available at load to the power accessible from the panel falls to be lower at low values of irradiation due to the sub-harmonic oscillations in the duty cycle control signal from the MPP tracking algorithm. 
Table I. Performance of MPPT Boost Converter

\begin{tabular}{|c|c|c|c|c|c|c|}
\hline S. No. & $\begin{array}{c}\text { Irradiation } \\
\left(\mathbf{W} / \mathbf{m}^{2}\right)\end{array}$ & $\begin{array}{c}\text { Efficiency of } \\
\text { MPPT }\end{array}$ & $\begin{array}{c}\text { \% of Oscillations } \\
\text { around MPP to Max. } \\
\text { Power }\end{array}$ & $\begin{array}{c}\text { \%Peak-Peak Output } \\
\text { Voltage Ripple (V) }\end{array}$ & $\begin{array}{c}\text { Conversion } \\
\text { Efficiency } \\
(\%)\end{array}$ & $\begin{array}{c}\text { Utilization } \\
\text { efficiency (\%) }\end{array}$ \\
\hline 1 & 1000 & 98.8 & 6.2 & 0.03 & 91.3 & 90.2 \\
\hline 2 & 800 & 96.65 & 6.4 & 0.053 & 91.6 & 88.53 \\
\hline 3 & 600 & 95.6 & 8.3 & 0.036 & 91.9 & 87.85 \\
\hline 4 & 400 & 94.5 & 15.5 & 0.048 & 92.6 & 87.5 \\
\hline 5 & 200 & 92 & 16 & 0.063 & 93.5 & 86 \\
\hline
\end{tabular}

\section{CONCLUSION}

The nonlinear dynamics the boost MPP tracker controlled by the popular $\mathrm{P}$ and $\mathrm{O}$ algorithm has been studied. It has been observed that the system controlled by the duty cycle signal form $\mathrm{P}$ and $\mathrm{O}$ algorithm preserve its stable periodic operation for higher values of irradiation during peak hours. The system has been seen to eventually lose its stability and enter into chaotic operation through quasi periodicity for lower values of irradiation during dawn and dusk. The analyses of nonlinear dynamics have been portrayed through time domain waveforms and phase portraits of the state variable system.

The performance of the solar PV MPPT system has been tabulated and found to provide an enhanced stable operation during peak hours and becomes oscillatory during lower values of irradiations. The exploration of chaotic behaviour of dc-dc converter in MPPT applications have been opened up to acclaim a wide scientific research domain for the design and control of the converters in the stable operating region for a prolonged range of environmental changes. The analysis has been presented to exploration the non- linear operation of the solar PV system and entails to suggest possible range of operation over the available changes in irradiation in the perspective of enhancing the use of solar PV system in real world applications.

\section{ACKNOWLEDMENTS}

The authors thank the authorities of Annamalai University for providing the necessary facilities to accomplish this piece of work

\section{REFERENCES}

[1] Amri, F., 2018, "Renewable and non-renewable energy and trade into developed and developing countries", Quality \& Quantity.

[2] Yang, J., Liu, J., Fang Z., and Liu, W., 2018, "Electricity scheduling strategy for home energy management system with renewable energy and battery storage: a case study", IET Renewable Power Generation, 12(6), pp. 639-648.

[3] Zrelli, M., 2016, "Renewable energy, non-renewable energy, carbon dioxide emissions and economic growth in selected Mediterranean countries",
Environmental Economics and Policy Studies, 19(4), pp. 691-709.

[4] 'Renewable Energy Policies in a Time of Transition' developed by IRENA, OECD/IEA and REN21 (2018).

[5] Bakhtiari H., and Naghizadeh, R., 2018, "Multicriteria optimal sizing of hybrid renewable energy systems including wind, photovoltaic, battery, and hydrogen storage with $\varepsilon$-constraint method", IET Renewable Power Generation, 12(8), pp. 883-892.

[6] Du, Q., Gang, W., Wang, S., Wang J., and Xu, X., 2017, "Application of Distributed Energy Systems in Subtropical and High Density Urban Areas", Energy Procedia, 142, pp. 2870-2876.

[7] Blake, S., and O'Sullivan, D., 2018, "Optimization of Distributed Energy Resources in an Industrial Microgrid", Procedia CIRP, 67, pp. 104-109.

[8] Youngil Kim., Junda Zhao., Sungjin Kim., and Robert J. Harrington., 2017, "Power Management Strategy for Residential Housing Connected to the Rooftop Solar PV", Proc. IEEE Conference on Technologies for Sustainability, Phoenix, AZ, USA.

[9] Liu, J., Li, J., Wu J., and Zhou, W., 2017, "Global MPPT algorithm with coordinated control of PSO and INC for rooftop PV array", The Journal of Engineering, 2017(13), pp. 778-782.

[10] Arsalan, M., Iftikhar, R., Ahmad, I., Hasan, A., Sabahat K., and Javeria, A., 2018, "MPPT for photovoltaic system using nonlinear backstepping controller with integral action", Solar Energy, 170, pp. 192-200.

[11] Ahmad Alzahrani, Pourya Shamsi, and Mehdi Ferdowsi and Cihan Dagli, 2017, "Chaotic Behavior of DC-DC Converters", Proc. 6th International Conference on Renewable Energy Research and Applications, San Diego, CA, USA, pp. 1013-1018.

[12] Chang, C., Zhao, X., Yang F., and Wu, C., 2016, "Bifurcation and chaos in high-frequency peak current mode Buck converter", Chinese Physics B,25(7), pp. 070504-1-070504-8.

[13] Łukasz Kocewiak, Claus Leth Bak, and Stig MunkNielsen, 2007, "Bifurcations and Chaos in a Pulse 
Width Modulation Controlled Buck Converter", Proc. of the 6th EUROSIM Congress on Modelling and Simulation, Ljubljana, Slovenia, pp. 1-6.

[14] Xuesong Feng, Chuang Bi, Yong Xiang, and Qian Zhang, 2013, "Dynamical Analysis of the DCM Buck Converter", Proc. International Conference on Communications, Circuits and Systems, Chengdu, China, pp. 442-445.

[15] Gurbina, M., Ciresan, A., Lascu, D., Lica S., and PopCalimanu, I., 2018, "A New Exact Mathematical Approach for Studying Bifurcation in DCM Operated dc-dc Switching Converters", Energies, 11(3), pp. 663-1-663-25.

[16] Premalatha, L., and Mirunalini, 2011, "Analysis of Chaos and EMI in a DC-DC Buck BoostConverter with Hard and Soft switching", Int. J. on Recent Trends in Engineering and Technology, 6(2), pp. 4246.

[17] Demirbaş, Ş., Fidanboy, H., and Kurt, E., 2016, "Exploration of the Chaotic Behaviour in a BuckBoost Converter Depending on the Converter and Load Elements", Journal of Electronic Materials, 45(8), pp. 3889-3899.

[18] Yi Jia, and Wei Xueye, 2002, "Chaos in Switch Control of a Current-Mode Cuk Converter", Proc. 2nd International Workshop on Autonomous Decentralized System, Beijing, China, pp-267-272.

[19] Sundaramoorthi, S., Saravanan, S., Karunanithi, K., and Praveenkumar S., 2017, "Investigation and Control of Chaos in DC-DC NOEL Converter Using Slope Compensation Method", Proc.International Conference On Intelligent Techniques In Control, Optimization And Signal Processing, Srivilliputhur, India.

[20] Subashini, M., and Ramaswamy, M., 2017, "Bifurcation and Chaos in Converter Interfaces in Solar PV Systems-A Review", Journal of Engineering Science and Technology Review, 10(5), pp. 90-97.

[21] Samer, S., Ahmed M., Mohieddine, B., and Shehab, A., 2012, "A Matlab/Simulink-Based Photovoltaic Array Model Employing SimPowerSystems Toolbox", Journal of Energy and Power Engineering, 6(2012), p. 1965-1975.

[22] Tekeshwar Prasad Sahu, Dixit T.V., and Ramesh Kumar, 2014, "Simulation and Analysis of Perturb and Observe MPPT Algorithm for PV Array Using CUK Converter" Advance in Electronic and Electric Engineering, 4(2), pp. 213-224. 